\title{
AVALIAÇÃO DA QUALIDADE MICROBIOLÓGICA DO GENGIBRE "IN NATURA" COMERCIALIZADO NA REGIÃO METROPOLITANA DE CURITIBA, PR AVALIAÇÃO DA QUALIDADE MICROBIOLÓGICA DO GENGIBRE "IN NATURA" COMERCIALIZADO NA REGIÃO METROPOLITANA DE CURITIBA, PR
}

\author{
ELPO, E. R. S. ${ }^{2 *}$; NEGRELLE, R. R. B. ${ }^{3 ;}$ GOMES, E. C. ${ }^{2}$ \\ 'Parte da tese de Doutorado em Agronomia - Produção Vegetal - UFPR \\ ${ }^{2}$ Doutora em Produção Vegetal - UFPR; Professora do Departamento de Saúde Comunitária, Laboratório de Saúde Pública - UFPR \\ * Correspondência do autor: Departamento de Saúde Comunitária. Universidade Federal do Paraná. Rua Padre Camargo, 280 - 70 andar. Alto da \\ Glória, Curitiba, Paraná, Brasil, CEP: 80.060-240 e-mail: erselpo@ufpr.br/erselpo@aol.com \\ ${ }^{3}$ Doutora em Ecologia; Professora do Departamento de Botânica, Laboratório OIKOS - UFPR
}

Recebido em: 08/2004 Aprovado em: 09/2004

\begin{abstract}
RESUMO
Analisou-se 10 amostras de gengibre "in natura" com objetivo de caracterizar o perfil microbiológico deste produto comercializado na região metropolitana de Curitiba, PR (Brasil). Para tanto, foram realizadas a determinação do número mais provável (NMP) de coliformes totais, coliformes a $45^{\circ} \mathrm{Cl}$ g e Escherichia coli, e a presença de Salmonella sp em 25 gramas. Os resultados indicaram que $100 \%$ das amostras atenderam ao padrão da legislação vigente para Salmonella sp, enquanto que $30 \%$ das amostras de gengibre enquadradas como raízes, tubérculos e similares, e cerca de $50 \%$ das amostras como especiarias, temperos, condimentos e similares apresentaram coliformes a $45^{\circ} \mathrm{C} / \mathrm{g}$. Destas amostras analisadas, $20 \%$ confirmaram a presença de Escherichia coli. Observouse que todas as amostras mostraram elevados índices de coliformes totais, apesar de não haver limite máximo estabelecido pela legislação vigente. Os resultados obtidos podem ser indicativos de inadequações nos procedimentos de beneficiamento pós-colheita e de comercialização. Palavras-chave: gengibre, coliformes, Salmonella sp.
\end{abstract}

\begin{abstract}
Ten samples of natural ginger, commercialized in Curitiba, Paraná (Brazil), were analyzed for microbiological quality. The microbiological analysis measured the total coliforms, $45^{\circ} \mathrm{C} / \mathrm{g}$ coliforms, the most probable number (MPN) of Escherichia coli and the presence of Salmonella sp. The results revealed that $100 \%$ of the samples complied with the required standard for the absence of Salmonella $\mathrm{sp}$. On the other hand, $30 \%-50 \%$ had $45^{\circ} \mathrm{C} / \mathrm{g}$ coliforms and $20 \%$ of them contained Escherichia coli. It was observed that all the samples had a high value for the total coliforms. This is important since the current legislation does not establish any limits. The results obtained may indicate inadequate procedures for post-harvesting and commercial handling.

keywords: ginger, coliforms, Salmonella sp.
\end{abstract}

\section{INTRODUÇÃO}

O Paraná destaca-se em nível nacional como maior produtor de gengibre "in natura" sendo Morretes o município de maior produção em nível estadual, com uma produtividade média de 18,0 t/ha - safra 01/02 representando cerca de 70\% a 90\% do volume de exportações brasileiras de gengibre "in natura" e praticamente a totalidade do gengibre que abastece a Região Metropolitana de Curitiba - PR (PARANÁ, 2003).

Apesar de ser uma cultura de relativa importância em nível estadual, pesquisas de campo junto a produtores e estabelecimentos de comercialização evidenciaram sérios problemas no que diz respeito à qualidade e adequabilidade das edificações e instalações, manipuladores, embalagem, armazenamento e inclusive a inexistência de laudo laboratorial atestando o controle de qualidade do produto "in natura" (ELPO, 2004b, ELPO, 2004c). É fato concreto que a qualidade dos procedimentos ao longo da cadeia de produção e comercialização é um forte determinante da qualidade final do produto disponível consumidor. Quando estas condições são inadequadas, gera-se um produto de má 
qualidade, que poderá, entre outros problemas, veicular vários microrganismos patogênicos ao consumidor (WORLD HEALTH ORGANIZATION - WHO, 1992).

Dentre os principais microrganismos potencialmente patogênicos encontrados em vegetais estão a Salmonella sp, Escherichia coli, ambos associados à contaminação fecal (WHO, 1992). Siqueira (1995), afirma que os coliformes diferenciam-se em coliformes totais e coliformes fecais, onde o índice de coliformes totais é utilizado para avaliar as condições higiênicas, sendo que altas contagens significam contaminação pós-processamento, limpeza e sanificação deficientes, tratamentos térmicos ineficientes ou multiplicação durante o processamento e estocagem. Já o índice de coliformes fecais é empregado como indicador de contaminação fecal, ou seja, condições higiênico-sanitárias, visto presumir-se que a população deste grupo é constituída de uma proporção de Escherichia coli, que tem seu habitat exclusivo no trato intestinal do homem e de outros animais de sangue quente, sendo assim a mais importante indicadora de contaminação fecal, ou melhor, a espécie que quando presente garante o contato direto do alimento com fezes (GUERREIRO, 1984).

Hoje se sabe que, além de existirem limites condenatórios já padronizados (BRASIL, 2001), a presença da bactéria Escherichia coli, representante principal dos coliformes, põe em risco a saúde pública, por possuir sorogrupos cuja patogenicidade é bastante conhecida (RIBEIRO et al., 1999).

O grupo coliforme compreende todas bactérias anaeróbicas facultativas, gram negativas, não formadoras de esporos, com capacidade para fermentar a lactose com produção de ácido e gás a $35^{\circ} \mathrm{C}$ dentro de 48 horas. Pertencem a este grupo, os gêneros, Citrobacter, Enterobacter e Klebsiella (REINHARDT, 1984).

A Salmonella sp é um microrganismo amplamente difundido na natureza, sendo o homem e animais seus principais reservatórios naturais. Trata-se de um patógeno muito envolvido em casos e surto de doenças de origem alimentar em diversos países. JAY (2000) menciona que esse agente, dentre os bastonetes gram-negativos que causam gastroenterites de origem alimentar, é o mais importante. A febre tifóide, extremamente comum no início do século XX, está agora esquecida nos Estados Unidos. Esta conquista deveu-se a utilização de desinfecção da água, pasteurização de leite e demais avanços higiênicos na produção de alimentos. Entretanto, uma infecção emergente causada por cepas não tifóides da Salmonella vem aumentando a incidência, década a década, desde a Segunda Grande Guerra Mundial (TAUXE，1997).

As principais causas que determinam aumento da salmonelose veiculada por alimentos são: aumento de elaboração de produtos em forma de massa, que favorece a disseminação da Salmonella; os procedimentos inadequados de armazenamento, que devido às atuais condições de vida são acumulados em excesso; o costume cada vez mais freqüente de comer produtos crus ou insuficientemente aquecidos; o aumento do comércio internacional; a diminuição de resistência às infecções, devido ao aumento dos níveis de higiene pessoal (JAY, 1994); mudanças gerais de hábitos (TAORMINA et al., 1999). Os hábitos alimentares da população podem influenciar a epidemiologia das salmoneloses, como a ingestão de alimentos crus, ou levemente aquecidos e conservados à temperatura ambiente, sendo causas da enfermidade (FRANCO e LANDGRAF, 1996).

O principal habitat da Salmonella sp é o trato intestinal de animais, tais como aves, répteis, animais de granja, pessoas e insetos (FRANCO e LANDGRAF, 1996; JAY, 2000). Como formas intestinais, também podem se encontrar na água. Quando a água utilizada nos alimentos está contaminada por insetos ou por outros meios, e contamina pessoas, fecha- 
se o ciclo na natureza (TAUXE, 1997).

Os principais sintomas da salmonelose são náuseas, vômitos, dor abdominal e diarréia, apresentando um período de incubação entre 12 e 36 horas, podendo, em alguns casos, ser mais curto (FRAZIER e WESTHOFF, 1993). No adulto, algumas patologias pré-existentes, como a AIDS e a esquistossomose, podem agravar a doença. Em crianças pequenas e recém-nascidas, a salmonelose pode ser bastante grave (FRANCO e LANDGRAF, 1996).

Dentro do setor industrial ou comercial, vários fatores podem contribuir na contaminação por salmonelas. Entre eles, pode-se destacar a presença de roedores e moscas. Os roedores infectados podem contaminar com suas fezes os alimentos não protegidos e, desta forma, disseminar as salmonelas. As moscas são importantes veiculadores do microrganismo, uma vez que pousam tanto em fezes contaminadas como nos produtos alimentícios (FRAZIER e WESTHOFF, 1993).

Diante do exposto e da alta potencialidade de contaminação do gengibre "in natura" evidenciada em estudos prévios, organizou-se a pesquisa cujos resultados são aqui apresentados. Especificamente, visou-se:

- Avaliar a qualidade microbiológica do gengibre "in natura" comercializado na região metropolitana de Curitiba, PR, no que se refere à determinação do número mais provável de coliformes totais, de coliformes a $45^{\circ} \mathrm{C}$ e a pesquisa de Salmonella sp.

- Confrontar os dados obtidos desta análise aos padrões microbiológicos estabelecidos pela legislação vigente e propor alternativas de solução, quando pertinentes.

\section{MATERIAL E MÉTODOS}

\section{1 Área de amostragem}

O trabalho foi realizado em estabelecimentos comerciais (CEASA/PR, Carrefour Com. Ind. Ltda., Companhia Brasileira de Distribuição (CBD), Sonae Distribuição Brasil S/ A., Mercado Municipal de Curitiba e feiras-livres) da região metropolitana de Curitiba, PR. Esta região foi selecionada devido à detecção prévia de ser pólo de convergência para comercialização do gengibre "in natura" (ELPO, 2004c), produzido nas áreas de cultivo do Estado do Paraná, em especial o litoral paranaense.

\subsection{Coleta das amostras}

As amostras de gengibre "in natura" procedentes da Região Metropolitana de Curitiba - PR, denominadas de A, B, C, D, E, F, G, H, I e J foram coletadas no período de outubro de 2001 a outubro de 2002, em 9 locais de comercialização de Curitiba, as quais foram devidamente transportadas para o Laboratório da disciplina de Saúde Pública do Curso de Farmácia da Universidade Federal do Paraná para serem analisadas.

\subsection{Análises laboratoriais}

As determinações microbiológicas de coliformes a $45^{\circ} \mathrm{C}$ e Salmonella $\mathrm{sp}$ foram efetuadas conforme métodos preconizados em VANDERZANT e SPLITTSTOESSER (1992), FDA (1995) e SILVA et al. (1997), explicitados a seguir: 


\subsubsection{Coliformes totais e Coliformes a $45^{\circ} \mathrm{C}$}

Foi usada a técnica dos tubos múltiplos, com três séries de três tubos em cada diluição $\left(10^{-1}, 10^{-2}\right.$ e $\left.10^{-3}\right)$. Usou-se como meio presuntivo o Caldo Lauril Sulfato Triptose (LST), com incubação a $35^{\circ} \mathrm{C}$ (24-48 horas). Após leitura, os tubos positivos, que apresentaram gás foram repicados para Caldo Lactosado Verde Brilhante Bile 2\% (VB) e Caldo EC, os quais foram incubados a $35^{\circ} \mathrm{C}$ (24-48 horas) e a $45^{\circ} \mathrm{C}$ em Banho-Maria (24-48 horas), respectivamente. A determinação do número mais provável (NMP/g) de coliformes totais e a $45^{\circ} \mathrm{C}$ foi feita pela Tabela de Hoskins (SPECK, 1984).

\subsubsection{Escherichia coli}

Uma alíquota dos tubos contendo EC, que apresentavam turbidez com gás no interior do tubo de Durhan, foi semeada em placas de petri contendo Ágar Eosina de Metileno e incubada a $35^{\circ} \mathrm{C}$ (24 horas). As colônias suspeitas de Escherichia coli foram confirmadas pela série bioquímica e incubadas a $35^{\circ} \mathrm{C}$ (24 horas), conforme o kit para identificação de enterobactérias (Newprov, 2002), contendo cinco tubos com os seguintes meios de cultura: EPM (determinação da urease, produção de $\mathrm{H}_{2} \mathrm{~S}$, gás, (desaminação do triptofano), MILi (motilidade, descarboxilação da lisina, produção de indol), MIO (motilidade, descarboxilação da ornitina e indol), Citrato de Simmons (prova de utilização do substrato) e Rhamnose (verificou se o bacilo gram negativo fermenta ou não este açúcar).

\subsubsection{Salmonella $\mathrm{sp}$}

Foram homogeneizados 25 g de gengibre "in natura" em 225 mL de água peptonada tamponada a 1\%. Após a incubação a $35^{\circ} \mathrm{C}$ (24 horas), $1 \mathrm{~mL}$ dessa suspensão foi transferido para $10 \mathrm{~mL}$ de Caldo Selenito-Cistina e $1 \mathrm{~mL}$ para $10 \mathrm{~mL}$ de Caldo Tetrationato de Kauffmann e incubados a $42^{\circ} \mathrm{C}$ (24 horas). Após, foram realizadas semeaduras por esgotamento em placas de petri, contendo ágar SS (Salmonella-Shigella), ágar Hectoen e ágar xilose lisina desoxicolato (XLD). Foi feita incubação a $35^{\circ} \mathrm{C}$, por 24 horas. As colônias suspeitas foram identificadas em ágar ferro tríplice (TSI) e ágar lisina ferro (LIA).

\subsection{Legislação de referência para o confronto dos resultados}

Utilizou-se como referencial de análise a normatização vigente até agosto de 2001 Resolução - CNPPA No 12 - BRASIL, 1978 e a em vigência atual - Resolução - RDC No 12 BRASIL, 2001. Nesta análise, considerou-se tanto o gengibre enquanto rizoma quanto como especiaria ou condimento, dado que ambas as situações são ocorrentes na comercialização deste produto. A legislação anteriormente em vigor estabelecia, para raízes, tubérculos e rizomas, o limite máximo de $2 \times 10^{2} / g$ de bactérias do grupo coliforme de origem fecal e ausência de Salmonella sp em $25 \mathrm{~g}$ do alimento. Considerando-se condimentos ou temperos, esta mesma legislação preconizava ausência de bactérias do grupo coliforme de origem fecal em $1 \mathrm{~g}$ e ausência de Salmonella sp em $25 \mathrm{~g}$ do alimento. Atualmente, a legislação vigente estabelece para raízes, tubérculos e similares $10^{3}$ coliformes a $45^{\circ} \mathrm{C} / \mathrm{g}$ e ausência de Salmonella sp em $25 \mathrm{~g}$ do alimento. No tocante a especiarias, temperos, condimentos e molhos preparados e similares, preconiza $5 \times 10^{2}$ coliformes a $45^{\circ} \mathrm{C} / \mathrm{g}$ e ausência de Salmonella sp em $25 \mathrm{~g}$ do alimento. 


\section{RESULTADOS E DISCUSSÃO}

Verificou-se que todas as amostras de gengibre "in natura" (100\%) apresentaram índices superiores a $10^{3} / \mathrm{g}$ de coliformes totais (Tabela 1). Apesar de não estar estabelecido limite máximo de coliformes totais pelos órgãos competentes, esta constatação indica falta de condições higiênicas adequadas em alguma etapa da cadeia produtiva do gengibre. Também, é um fato que deve ser considerado como relevante na medida que a contaminação por coliformes pode constituir um risco à saúde do consumidor.

Considerando-se a legislação vigente, do total de 10 (dez) amostras de gengibre "in natura", 3 (30\%) apresentaram valores superiores aos permitidos (BRASIL, 2001) para presença de coliformes a $45^{\circ} \mathrm{C} / \mathrm{g}$, quando enquadradas no grupo de raízes, tubérculos e similares. Na categoria de especiarias, temperos, condimentos e molhos preparados, aproximadamente 5 (50\%) superaram os limites da respectiva legislação (Tabela 1).

Confrontando-se estes resultados com a legislação anterior, observou-se que a maioria das amostras de gengibre (90\%), quando enquadradas como rizomas, apresentavam-se fora dos padrões aceitáveis, estando apenas a amostra J (10\%) dentro destes padrões. Quando consideradas como condimentos ou temperos, 100\% destas amostras analisadas estavam em desacordo com esta legislação (Tabela 1).

TABELA 1 - Parâmetros microbiológicos de amostras de gengibre "in natura" comercializadas na Região Metropolitana de Curitiba, PR - Outubro 2001 a Outubro 2002.

\begin{tabular}{|c|c|c|c|c|}
\hline $\begin{array}{l}\text { Amostras de } \\
\text { gengibre } \\
\text { "in natura " }\end{array}$ & $\begin{array}{l}\text { Coliformes } \\
\text { Totais } \\
(\mathrm{NMP} / \mathrm{g})\end{array}$ & $\begin{array}{c}\text { Coliformes } \\
\text { a } 45^{\circ} \mathrm{C} \\
(\mathrm{NMP} / \mathrm{g})\end{array}$ & $\begin{array}{l}\text { E. coli } \\
\text { (NMP/g) }\end{array}$ & $\begin{array}{c}\text { Salmonella } \\
\text { sp/25g }\end{array}$ \\
\hline$A$ & $>1,1 \times 10^{3}$ & $>1,1 \times 10^{3 a, b, a, b}$ & $>1,1 \times 10^{3}$ & Ausência \\
\hline B & $>1,1 \times 10^{3}$ & $>1,1 \times 10^{3 a, b, a, b}$ & $<3$ & Ausência \\
\hline C & $>1,1 \times 10^{3}$ & $4,6 \times 10^{2 a, b, b}$ & $<3$ & Ausência \\
\hline D & $>1,1 \times 10^{3}$ & $>1,1 \times 10^{3 a, b, a, b}$ & $<3$ & Ausência \\
\hline $\mathrm{E}$ & $>1,1 \times 10^{3}$ & $2,4 \times 10^{2 a, b}$ & $<3$ & Ausência \\
\hline $\mathrm{F}$ & $>1,1 \times 10^{3}$ & $2,1 \times 10^{2 a, b}$ & $<3$ & Ausência \\
\hline G & $1,1 \times 10^{3}$ & $4,6 \times 10^{2 a, b, b}$ & $<3$ & Ausência \\
\hline $\mathrm{H}$ & $>1,1 \times 10^{3}$ & $2,1 \times 10^{2 a, b}$ & $<3$ & Ausência \\
\hline 1 & $>1,1 \times 10^{3}$ & $2,4 \times 10^{2 a, b}$ & $>1,1 \times 10^{3}$ & Ausência \\
\hline $\mathrm{J}$ & $>1,1 \times 10^{3}$ & $0,9 \times 10^{b}$ & $<3$ & Ausência \\
\hline $\begin{array}{c}\text { PADRÃO FEDERAL } \\
\text { (Brasil, 1978) }\end{array}$ & $\begin{array}{l}\text { Não estabelece } \\
\text { Limite máximo }\end{array}$ & $\begin{array}{l}\text { Máximo } 2 \times 10^{2} / \mathrm{g}^{a} \\
\text { Ausência em } 1 \mathrm{~g}^{\mathrm{b}}\end{array}$ & $\begin{array}{c}\text { Não } \\
\text { estabelece } \\
\text { Limite máximo }\end{array}$ & $\begin{array}{l}\text { Ausência }^{a} \\
\text { Ausência }^{\mathrm{b}}\end{array}$ \\
\hline $\begin{array}{l}\text { PADRÃO FEDERAL } \\
\text { (Brasil, 2001) }\end{array}$ & $\begin{array}{l}\text { Não estabelece } \\
\text { Limite máximo }\end{array}$ & $\begin{array}{c}\text { Máximo } 10^{3} / \mathrm{g}^{a} \\
\text { Máximo } 5 \times 10^{2} / \mathrm{g}^{b}\end{array}$ & $\begin{array}{c}\text { Não } \\
\text { estabelece } \\
\text { Limite máximo }\end{array}$ & $\begin{array}{l}\text { Ausência }^{a} \\
\text { Ausência }^{b}\end{array}$ \\
\hline
\end{tabular}

Nota: As indicações em vermelho referem-se às amostras que extrapolam os valores permitidos pela legislação anterior e em azul, que extrapolam os limites da legislação vigente, sendo:

a) grupo de alimentos: raízes, tubérculos e rizomas.

b) grupo de alimentos: especiarias, temperos, condimentos, molhos preparados e similares.

No detalhamento da análise de coliformes, confirmou-se a presença de Escherichia coli em duas amostras (20\%). Este fato reforça a existência de condições pré-existentes inadequadas afetas ao sistema de beneficiamento pós-colheita e comercialização (ELPO, 
2004a; ELPO, 2004b, ELPO, 2004c) e que poderiam estar associadas a esta contaminação. Segundo THATCHER e CLARCK (1973), GUERREIRO (1984) e PELCZAR (1996), o índice de coliformes é utilizado para avaliar as condições higiênicas, sendo que altas contagens significam contaminação pós-processamento, limpeza e sanificação deficientes.

Adicionalmente, DELAZARI (1979) enfatiza que os coliformes indicam processamento inadequado ou uma contaminação pós-processamento, mais provavelmente através dos manipuladores, instrumentos sujos, equipamentos, superfícies ou ainda da matéria-prima antes do processamento, que foram contaminados por contato humano, solo, esterco ou água contaminada por fezes.

De acordo com INTERNATIONAL COMMISSION ON MICROBIOLOGICAL SPECIFICATIONS FOR FOODS - ICMSF (1991) e BRYAN (1985), coliformes totais não são incluídos nas análises convencionais, por não serem bons indicadores de contaminação, podendo aparecer mesmo após a higiene das mãos. Conforme LEITÃO et al. (1971/1972), a presença de grande número de coliformes totais não é um indicativo de perigo para a saúde. Porém, segundo estes mesmos autores, a presença destes microrganismos demonstra a falta de boas práticas sanitárias, o que constitui um alerta de que será possível encontrar também diferentes patógenos, como por exemplo Shigella sp, vibriões e inclusive, como já anteriormente mencionada, a Escherichia coli. Esta última é considerada como representante principal dos coliformes, possuindo sorogrupos cuja patogenicidade é bastante conhecida (RIBEIRO et al., 1999). GUERREIRO (1984) e SIQUEIRA (1995) atribuem a presença de Escherichia coli em alimento como decorrente da contaminação por fezes, por se tratar de uma bactéria exclusiva do trato intestinal do homem e de outros animais de sangue quente.

A presença de Escherichia coli, registrada nas amostras de gengibre comercializadas em Curitiba, reforça a necessidade de revisão e melhor fiscalização das diferentes etapas da cadeia produtiva deste produto. Entretanto, este problema aparentemente não é exclusivo do gengibre comercializado em Curitiba, dado que outros autores também registram esta contaminação em outros locais. Por exemplo, cita-se SCHWAB et al. (1982), cujas análises registraram para o gengibre adquirido no comércio americano, como condimento, valores

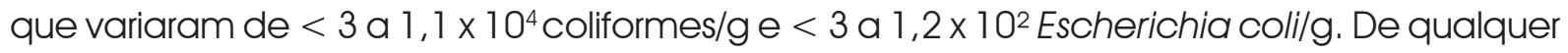
forma, a problemática no que diz respeito ao risco à saúde do consumidor é a mesma.

Afortunadamente, as amostras analisadas estavam isentas de Salmonella sp. (Tabela 1). A presença de Salmonella poderá dar origem a sérios processos infecciosos do trato intestinal, determinando que o alimento contaminado seja impróprio para o consumo (LEITÃO (1971). Porém, ressalta-se que a ocorrência de infecção dependerá de fatores predisponentes envolvidos (GUERREIRO, 1984).

\section{CONSIDERAÇÕES FINAIS}

Ressente-se na legislação brasileira vigente da falta de padrão para contagem de coliformes totais e Escherichia coli, pois estes parâmetros são importantes para a avaliação da qualidade do produto "in natura" e respectiva garantia de segurança para o consumidor. A ausência da obrigatoriedade destas análises ou maior tolerância para coliformes a $45^{\circ} \mathrm{C} /$ g aumenta o risco de exposição a patógenos importantes que freqüentemente estão associados às práticas inadequadas que determinam a contaminação de alimentos por coliformes fecais. 
Dada a situação de contaminação evidenciada, cabe aos órgãos competentes conscientizar os diferentes atores da cadeia produtiva sobre boas práticas de produção e comercialização, buscando identificar e aplicar medidas para minimizar os fatores geradores desta problemática. Cabe ao consumidor, exigir laudo de qualidade sanitária do produto a ser consumido.

\section{REFERÊNCIAS}

BRASIL. Ministério da Saúde. Secretaria de Vigilância Sanitária. Resolução da Comissão Nacional de Normas e Padrões para Alimentos - CNNPA n. 12, de 1978. Aprova Normas Técnicas Especiais do Estado de São Paulo, relativas a alimentos e bebidas. Diário Oficial da União. Brasília, 24 de julho de 1978, seção I, pł I, p. $11523-11525$. BRASIL. Ministério da Saúde. Secretaria de Vigilância Sanitária. Resolução - RDC n. 12, de 02 de janeiro de 2001. Regulamento técnico sobre padrões microbiológicos para alimentos. Diário Oficial, 10 de janeiro de 2001. BRYAN, F. L. Procedures to use during outbreaks of foods-borne disease. In: Lenette, E. H. (ed.) Manual Microbiology, 4. ed. Washington: American Society of Microbiology, 1985.

DELAZARI, I. Aspectos microbiológicos de alimentos desidratados. Boletim do Instituto Tecnológico de Alimentos, Campinas, v. 16, p. 227-260, 1979.

ELPO. E. R. S. Cadeia produtiva do gengibre (Zingiber officinale Roscoe) no Estado do Paraná: análise e recomendações para melhoria da qualidade. Curitiba, Paraná, 2004a. Tese de Doutorado em Ciências, Universidade Federal do Paraná. 180 p. In: CARACTERIZAÇÃO DO CULTIVO E BENEFICIAMENTO DO GENGIBRE (Zingiber officinale Roscoe) NO LITORAL DO ESTADO DO PARANÁ, BRASIL. Capítulo 5.

ELPO. E. R. S. Cadeia produtiva do gengibre (Zingiber officinale Roscoe) no Estado do Paraná: análise e recomendações para melhoria da qualidade. Curitiba, Paraná, 2004b. Tese de Doutorado em Ciências, Universidade Federal do Paraná. 180p. In: DIAGNÓSTICO DAS CONDIÇÕES HIGIÊNICO-SANITÁRIAS DO SISTEMA DE BENEFICIAMENTO PÓS-COLHEITA DO GENGIBRE "IN NATURA" NO LITORAL PARANAENSE, BRASIL. Capítulo 6.

ELPO. E. R. S. Cadeia produtiva do gengibre (Zingiber officinale Roscoe) no Estado do Paraná: análise e recomendações para melhoria da qualidade. Curitiba, Paraná, 2004c. Tese de Doutorado em Ciências, Universidade Federal do Paraná. 180p. In: QUALIDADE E ADEQUABILIDADE DOS LOCAIS DE COMERCIALIZAÇÃO DO GENGIBRE "IN NATURA" NA REGIÃO METROPOLITANA DE CURITIBA, PARANÁ, BRASIL. Capítulo 7.

FDA. FOOD AND DRUG ADMINISTRATION. Bacteriological analytical manual. 8 ed. Association of Official Analytical Chemists Internacional, USA, 1995.

FRANCO, B. D. G. M.; LANDGRAF, M. Microrganismos patogênicos de importância em alimentos. In: Microbiologia de Alimentos. São Paulo: Atheneu, 1996. 182p.

FRAZIER, W. C.; WESTHOFF, D. C. Microbiologia de los alimentos. 4. ed. Zaragoza: Editorial Acribia, 1993. 681p.

GUERREIRO, M. G. Bacteriologia Especial: com interesse à saúde pública. Porto Alegre: Sulina, 1984.

ICMSF. INTERNATIONAL COMMISSION ON MICROBIOLOGICAL SPECIFICATIONS FOR FOODS. El sistema de analisis de riesgos y puntos criticos. Zaragoza: Acribia, p. 77-109, 1991.

JAY, J. M. Microbiologia moderna de los alimentos. 3.ed. Zaragoza: Acribia, 1994. 491 p.

JAY, J. M. Modern Food Microbiology. 6. ed. Maryland: Aspen, 2000. 679 p.

LEITÃO, M. F. F. Métodos de identificação de Salmonella em alimentos. Boletim do Instituto Tecnológico de Alimentos, Campinas, n. 25, p.29, 1971.

LEITÃO, M. F. F.; ROMEU, A. P.; CRUZ, R. R. Coliformes totais e fecais como indicadores de contaminação. Coletânea do Instituto de Tecnologia de Alimentos, Campinas, v. 9, p. 01-02, 1971.

LEITÃO, M. F. F.; ROMEU, A. P.; CRUZ, R. R. Coliformes totais e fecais como indicadores de contaminação. Coletânea do Instituto de Tecnologia de Alimentos, Campinas, v. 9, p. 13-21, 1972.

NEWPROV. Manual de identificação de enterobactérias. Paraná: Newprov, 2002.

PARANÁ. Secretaria de Estado da Agricultura e do Abastecimento do Paraná - SEAB. Departamento de Economia Rural - DERAL. Área, produção e valor bruto da produção de gengibre no Estado do Paraná, Safra 01/02. Curitiba, 2003.

PELCZAR, M. J. Microbiologia. v. 1, São Paulo, p. 576, 1996.

REINHARDT, N. M. Condições sanitárias e classificação das águas do mar destinadas à balneabilidade de praias do Estado do Paraná. São Paulo, 1984. Tese de Doutorado em Saúde Pública, Universidade de São Paulo. $105 p$.

RIBEIRO, M. G.; PINTO, J. P. A. N.; SILVA, E. O. T. R. Escherichia coli O157:H7 de hambúrguer, leite e outros gêneros alimentícios à colite hemorrágica e síndrome urético-hemolítica. Revista Higiene alimentar, São Paulo, v. 13, n.66/ 67, p. 88-99, 1999.

SCHWAB, A. H. et al. Microbiological quality of some spices and herbs retail markets. Applied and Environmental Microbiology, Washington, v. 44, n. 3, p. 627-630, 1982.

SILVA, N.; JUNQUEIRA, V. C. A. ; SILVEIRA, N. F. A. Manual de Métodos de Análise Microbiológica de Alimentos. São Paulo: Livraria Varela, 1997. 294p. 
SIQUEIRA, R. S. Manual de Microbiologia dos Alimentos. EMBRAPA. Centro Nacional de Pesquisa de Tecnologia Agroindustrial de Alimentos. Rio de Janeiro, p. 73-130. 1995.

SPECK, M. L. Compedium of methods for the microbiological examination of foods. Washington D.C. American Public Health Association, 1984. 914p.

TAORMINA, P. J.; BEUCHAT, L.; SLUTAKERT, L. Infections associated with eating seed sprouts: an international concern. emerging infectious diseases. v.5, n.5, p.626-634, 1999.

TAVEIRA MAGALHÃES, M. et al. Gengibre (Zingiber officinale Roscoe) brasileiro: aspectos gerais, óleo essencial e oleoresina. Parte 1 - aspectos gerais, óleo essencial. Ciência e Tecnologia de Alimentos, Campinas, v. 17, n. 1, p. 64-69, Jan-Abr. 1997.

THATCHER, F. S.; CLARCK, D. S. Análisis microbiológico de los Alimentos. Zaragoza: Acribia, 1973. 271 p.TAUXE, R. V. Emerging foodborne diseases: Envolving Public Health Challenge. Emerging Infections Diseases. v. 3, n. 4, p. 425433, 1997.

VANDERZANT, C.; SPLITTSTOESSER, D. F. Compedium of methods for the microbiological examination of foods. 3. ed. Washington, DC.: APHA, p.325-369, 1992.

WHO. WORLD HEALTH ORGANIZATION. Quality control methods for medicinal plant materials. Switzerland, 1992. $71 \mathrm{p}$. 